\title{
ENTRE LA TIERRA Y EL CIELO: EL PRECIO DE LA SALVACIÓN ENTERNA PARA LAS FAMILIAS CAMPESINAS DE SAHAGÚN EN EL SIGLO XVIII.
}

\author{
JuAn Manuel Bartolomé Bartolomé \\ Universidad de León

\section{Resumen}

Estudio a través de las partijas o particiones de bienes de las actitudes religiosas ante la muerte y las cantidades económicas destinadas por las familias campesinas de Sahagún (León) en la segunda mitad del siglo XVIII a afrontar los gastos de la muerte y la salvación del alma. También se analiza la incidencia de dichos gastos en las haciendas familiares y en las legítimas entregadas a los hijos y finalmente los bienes con que se pagaban.

\section{Palabras Clave}

Partijas o particiones de bienes, Sahagún, siglo XVIII, muerte, herencia,campesinado, religiosidad popular.

\begin{abstract}
We have atteyped to study the religious attitudes towards death and the amount of money which peasant families spent on their burilas, funerals and prayers in the second half part of the 18 th century in the area of Sahagún (Leon). We have also anlized how the families inherances and share-outdeeds are distributed to cover these expenses.
\end{abstract}

\section{Key Words}

Share-out-deeds, Sahagún, 18th century, death, inherance, peasant, popular religion.

Uno de los temas preferidos en la historiografía española modernista a partir de los años 70 del siglo XIX, siguiendo los estudios y pautas metodológicas realizados en Europa, sobre todo por los historiadores franceses ${ }^{1}$,

${ }^{1}$ Cabe recordar los trabajos pioneros de F. LEBRUN, Les hommes et la mort en Anjou aux XVIe et XVIIIe siécles. Essai de démographie et de psychologie historiques, París, 1971. M. Vovelle, Pièté baroque et deschristianisation en Provence au XVIIe siècle, París, 1973. P. CHAUNU, La mort a Paris XVIe , XVII, XVIIIe siècle, París, 1978. 
fue el análisis de las actitudes colectivas ante la muerte y la religiosidad popular'.

A pesar de esta profusión de estudios ${ }^{3}$, sin embargo, uno de los aspectos donde se ha profundizado menos es en la importancia económica y hereditaria que las actitudes ante la muerte representaban para las haciendas familiares y cómo podían repercutir los gastos destinados a la salvación del alma en las futuras hijuelas dejadas a los herederos/as ${ }^{4}$. Enlazando, por lo tanto, con la historia de la familia e incluso con su campo más prometedor, el constituido por el análisis de sus reproducciones sociales ${ }^{5}$.

En consecuencia, utilizando como principal fuente de información las partijas de los bienes del campesinado leonés de Tierra de Campos ( comarca de Sahagún ) y no los tradicionales testamentos ${ }^{6}$, nos hemos planteado en este trabajo abordar los siguientes objetivos: En primer lugar, tratar de averiguar el gasto a nivel global destinado en definitiva a la salvación del alma por las

\footnotetext{
${ }^{2}$ Resultaría muy difícil citar aquí la gran producción de estudios surgidos sobre el tema desde las aportaciones iniciales de T. EGIDO Y B. BARREIRO. De ahí, que para una relación exhaustiva, e incluso crítica de los mismos, remitimos al excelente artículo de M. GARCÍA FERNÁNDEZ, "Tendencias historiográficas recientes sobre religiosidad e historia de la muerte y de las mentalidades", en Historia a Debate. Tomo II. (Carlos Barros, editor), A Coruña, 1.985, pp. 143-157.

${ }^{3}$ Hasta tal punto que según T. EGIDO en los momentos actuales"...tenemos suficientes noticias de mortajas, de hábitos de una u otra orden más o menos implantada en los lugares analizados, de albaceas, de mandas, de elecciones de sepulturas y su categorías, de acompañamientos de curas y pobres. Y sabemos mucho, muchísimo de misas ...", T. EGIDO, "la religiosidad de los españoles (siglo XVIII)", Congreso Internacional Carlos III y su siglo, Tomo II, Madrid, 1.990, pág. 790.

${ }^{4}$ M. GARCÍA FERNÁNDEZ, "Tendencias historiográficas...", art. cit., pp. 144-145.

${ }^{5}$ En la línea metodológica de los relevantes estudios de G. DELILLE sobre el reino de Nápoles, -Famile et propiété dans le royaume de Naples dans l'Ancien Regime, 1.985, Paris- o los de B. DEROUET sobre Francia - sobre todo "La transmissión égalitaire du patrimoine dans la France rurale (XVIe-XIX siécles): nouvelles perspectives de recherche", en Familia , Casa y Trabajo , F. CHACÓN JIMÉNEZ Y L. FERRER I ALÓS (eds.), Universidad de Murcia, pp.73-92- y los de J. M. PÉREZ GARCÍA -"Estructuras familiares, prácticas hereditarias y reproducción social en la Vega Baja del Esla (1700-1850)", en Un modelo social leonés en crecimiento. La Vega Baja del Esla entre 1700 y 1850. Universidad de León, 1.988, págs. 85-109- y F. GARCÍA GONZÁLEZ, Las estrategias de la diferencia. Familia y reproducción social en la Sierra. (Alcaraz, siglo XVIII), Madrid, 2.000- para España.

${ }^{6}$ Las partijas que disponemos tienen la virtud de especificar todos los gastos reales efectuados en el entierro, misas, etc., mientras que en los testamentos las demandas realizadas por el testador/a son más teóricas, en cuanto que su posterior cumplimiento de lo solicitado (tipo de entierro, misas demandadas, etc.) va a depender de los bienes que deja disponibles el difunto/a y de su cabimiento en el quinto.
} 
familias campesinas en la segunda mitad del siglo XVIII. En segundo lugar, nos interesa poner en relación el gasto dedicado a pagar el entierro, misas, ofertas, etc., con los bienes o riquezas familiares. Es decir, tanto con los bienes patrimoniales, como sobre todo con los bienes líquidos (los que dejaba el difunto/a a sus herederos/as una vez unidos a los gananciales que les correspondían los dotales y parafernales aportados al matrimonio y descontadas las posibles deudas). Y en tercer lugar, un objetivo de gran relevancia es acercarnos a la detracción que pueden suponer estos gastos de las actitudes ante la muerte en las hijuelas económicas dejadas en herencia a los hijos.

Como ya se ha adelantado la fuente principal sobre la que hemos basado este estudio han sido las partijas de bienes del campesinado leonés de la comarca de Sahagún (Tierra de Campos ) en la segunda mitad del siglo XVIII ${ }^{7}$. Además, consideramos que el estudio propuesto puede ser importante en cuanto que al tratarse del campesinado y no de uno de los grupos elitistas de la sociedad contribuye a completar el panorama historiográfico modernista.

\section{EL GASTO GENERAL POR LA SALVACIÓN Y SUS PRINCIPALES BENEFICIARIOS.}

Como es conocido ${ }^{8}$ la herencia en Castilla se dividía en cinco partes, cuatro de las cuales debían forzosamente transmitirse a los descendientes y la quinta parte, que no se computaba como legítima, quedaba a la entera disposición del testador para darle el destino que estimara más oportuno. Es en este quinto de libre disposición donde tenían cabida los legados píos y de donde se sacaban los gastos destinados al entierro, misas, ofertas, etc 9 . De tal forma, que como ya hemos señalado a veces solía ocurrir que las demandas efectuadas en los testamentos respecto a su entierro, número de misas, etc., no podía cumplirse en

\footnotetext{
${ }^{7}$ En total las partijas que nos relacionan de una forma más pormenorizada los gastos de entierro, misas, ofertas, mandas religiosas, etc., son 90 . Archivo Histórico Provincial de León (A.H.P.L), Protocolos Notariales de Sahagún.

${ }^{8}$ Ver E. GACTO, "El grupo familiar en la Edad Moderna en los territorios del Mediterráneo Hispánico: Una visión jurídica", en La familia en la España Mediterránea (S.XV-XIX), Barcelona, 1.987, págs. 52 y ss.

${ }^{9}$ A veces estos gastos se incluían cuando se hacía relación de las deudas de los bienes patrimoniales y no en el quinto líquido del difunto/a.
} 
su totalidad y tenían que rebajarse debido a que excedían el quinto de los bienes líquidos ${ }^{10}$.

Partidas significativas de los patrimonios eran destinadas a sufragar el importante coste de la muerte. Así a nivel general en las familias campesinas de la comarca de Sahagún en la segunda mitad del siglo XVIII estos gastos llegaban a suponer un 4,9\% de los bienes patrimoniales ${ }^{11}$. Ahora bien, si hallamos la relación con los bienes líquidos de los difuntos/as, lo cual consideramos más relevante ya que están descontadas las deudas patrimoniales y es en definitiva la cantidad dejada en herencia, nos encontramos con que supone un 10,2\% de los bienes líquidos ${ }^{12}$. Es decir, que un $10 \%$ de los bienes eran sustraídos a las legítimas y eran destinados a lograr la salvación eterna.

\footnotetext{
${ }^{10}$ Aunque se supone que los testadores tenían un conocimiento de la situación económica familiar no es raro encontrar entre el campesinado demandas que superan y no se ajustan a la realidad económica y que posteriormente deben aminorarse para poder tener cabida en el quinto. Por otra parte, es normal que ocurra más en este tipo de economías más precarias como son las del campesinado y sobre todo en el sector del campesinado con bienes líquidos más modestos (medias de 2.070 reales) y en cambio sean más raros entre los campesinos con niveles patrimoniales y de bienes líquidos más elevados (por encima de los 5.000 reales de media). Así, por ejemplo, Lorenzo Martínez, vecino de Sahagún, en su testamento había solicitado un tipo de entierro y una demanda de misas y oferta que suponían una cantidad total de 561 reales y como éstos superan con creces el quinto de sus bienes (308,4 reales) sólo se le efectúa un entierro, etc., en 1775, de 392 reales. A veces es la propia viuda/o la que se encarga de cubrir los gastos a mayores del quinto, bien por motivos afectivos o bien por tratarse de gastos generados por actividades que ya han sido realizadas y que no se pueden recortar o suprimir en un futuro. Es el caso de Patricio de la Huerta, vecino de San Pedro de las Dueñas, cuyo entierro, funeral, supera los 206, 6 reales del quinto de sus bienes líquidos (provenientes sobre todo de los bienes que había aportado al matrimonio, dotales y parafernales, ya que los gananciales tienen una balance negativo de 276 reales) y su viuda, Baltasara Felipe, se hace cargo de los gastos a mayores ( sepultura 15 reales, derechos del sacristán 5 reales, derechos del sacerdote 11 reales y derechos de la Cofradía de las Ánimas 19 reales). A.H.P.L, Antonio Mata, Cajas 44614462.

${ }^{11}$ En Valladolid M. García Fernández llega a estimar en un 3\% de los valores patrimoniales. M. GARCÍA FERNÁNDEZ, Herencia y patrimonio familiar en la Castilla del Antiguo Régimen (1650-1834). Efectos socioeconómicos de la muerte y la partición de bienes, Valladolid, 1.995, p.115. ${ }^{12}$ Por bienes líquidos entendemos la cantidad que resulta de los bienes aportados al matrimonio (dotales y parafernales) y los bienes gananciales obtenidos durante el matrimonio después de haber descontado las deudas a los mismos.
} 


\section{CUADRO 1}

EL GASTO GENERAL POR LA SALVACIÓN (reales)

\begin{tabular}{lcccccc}
\hline & $\begin{array}{c}\text { Entierro, } \\
\text { honras, etc. }\end{array}$ & Misas & Ofertas & $\begin{array}{c}\text { Séptimas } \\
\text { acostumbradas }\end{array}$ & $\begin{array}{c}\text { Mandas } \\
\text { religiosas }\end{array}$ & Novenarios \\
\hline $\begin{array}{l}\text { Total } \\
\text { reales }\end{array}$ & 13.488 & 15.018 & 10.944 & 188 & 140 & 54 \\
$\begin{array}{l}\text { Media } \\
\text { reales }\end{array}$ & 164,5 & 183 & 133,5 & 2,29 & 0,9 & 0,7 \\
$\%$ & 33,8 & 37,7 & 27,5 & 0,5 & 0,3 & 0,2 \\
\hline
\end{tabular}

Fuente: A.H.P.L. (82 casos)

Los gastos ocasionados por la muerte y salvación del alma a la hora de su análisis los podemos agrupar en los siguientes: gastos originados por el entierro, honras y cabo de año; los ocasionados por la solicitud de misas; los derivados de las ofertas; los de las mandas religiosas; los novenarios y las séptimas acostumbradas. De ellos las misas se llevaban, con un 37,7\% y 183 reales de media, las mayores cantidades del presupuesto, seguidos por el funeral con un $33,8 \%$ y 164,5 reales de media ${ }^{13}$. En un tercer puesto se sitúan las ofrendas, a las cuales se las denomina más como "ofertas", de pan y cera sobre la sepultura, donde se incluyen también los derechos que se deben pagar a las personas encargadas de llevarla, con un $27,5 \%$ y 133,5 reales de media ${ }^{14}$. El resto, séptimas acostumbradas, donde lo establecido eran los dos reales, mandas religiosas y novenarios suponían cantidades muy insignificantes, no superando el $0,5 \%{ }^{15}$.

\footnotetext{
${ }^{13}$ También eran las misas y el funeral las principales partidas en las zonas rurales de Valladolid durante la Edad Moderna con porcentajes inferiores a los nuestros pero superiores al $50 \%$, el 56,4\%. M. GARCÍA FERNÁNDEZ, Herencia y patrimonio familiar..., op. cit. pp. 123-125.

${ }^{14}$ Inferiores a las zonas rurales de Valladolid con un 30,8\%. Ibídem.

${ }^{15}$ Las mandas religiosas con un $0,3 \%$ y los novenarios con un $0,2 \%$ están por debajo de las zonas rurales de Valladolid. Ibídem.
} 


\section{CUADRO 2}

GASTOS DE ENTIERRO, HONRAS Y CABO DE AÑO (reales)

Sepultura Hábito Derechos del Cofradías Cera Derechos sacristan sacerdotes, religiosos, etc.

\begin{tabular}{lcccccc}
\hline $\begin{array}{l}\text { Total } \\
\text { reales }\end{array}$ & 1.288 & 2.856 & 122 & 1.898 & 2.372 & 4.952 \\
$\begin{array}{l}\text { Media } \\
\text { reales }\end{array}$ & 15,7 & 43,2 & 5 & 43,1 & 56,5 & 62 \\
$\%$ & 9,5 & 21,2 & 0,9 & 14 & 17,6 & 36,8 \\
\hline
\end{tabular}

Fuente: A.H.P.L. (82 casos)

Si exceptuamos las misas, las cuales serán objeto de un estudio más pormenorizado, son los gastos del funeral tal como hemos señalado los más cuantiosos aproximándose más que en las zonas rurales de Valladolid a los gastos en misas solicitadas ${ }^{16}$. De estos gastos del funeral (entierro, honras y cabo de año) la mayor partida se la llevan las cantidades pagadas a los sacerdotes por sus servicios, un $36,8 \%$ y 62 reales de media ${ }^{17}$. Le sigue, pero a una distancia muy apreciable, los derechos pagados por el hábito con que se requiere ser enterrado, un $21,2 \%{ }^{18}$. En tercer lugar, con un $17,6 \%$ y 56,5 reales de media, se sitúan los gastos dirigidos a la compra de cera para que ardiese durante los actos religiosos. El cuarto lugar lo ocupa, con un $14 \%$, el dinero destinado a

\footnotetext{
${ }^{16}$ Ibídem.

${ }^{17}$ Los derechos de los curas solían ser de 15 reales por los entierros, cuando además se incluían las honras y cabo de año se superaban los 70 reales. De todas formas hemos de precisar que cuando se incluyen las honras y cabo de año existe una gran diferencia de precios, oscilando entre 36 reales y 262 reales, lo cual no resulta extraño ya que por lo que conocemos, caso de Valladolid, se trata de cantidades fijas, incluso estipuladas en un Arancel General por los Sínodos Diocesanos, y que posteriormente se compartían y dividían entre los curas que asistiesen a dichos oficios. Ibidem, p.109-111.

${ }^{18}$ Hábito o mortaja que solía costar al igual que en Valladolid 44 reales y donde se especifica en algunos casos de mujeres la preferencia del hábito de San Francisco de Grajal o San Facundo de Sahagún. Este precio del hábito se repite en todos los casos consultados de la muestra excepto en Francisco Vecares, vecino de Sahagún, que sólo paga por la mortaja 20 reales. M. GARCÍA FERNÁNDEZ, Herencia y patrimonio familiar..., op. cit., p. 124. A.H.P.L., Protocolos Notariales.
} 
pagar las cofradías que asisten al entierro y funerales ${ }^{19}$. En penúltimo lugar con un $9,5 \%$ aparecen los derechos de sepultura que los familiares del fallecido/a debían pagar a las parroquias donde fueron enterrados ${ }^{20}$. Y finalmente, los derechos que se pagan a los sacristanes - imprescindibles porque eran los encargados del "rompimiento de la sepultura", de tocar las campanas, ayudar en misa, etc.- sólo representan el $0,9 \%$ y una media de 5 reales $^{21}$.

Por lo tanto, las familias campesinas terracampinas detraían de sus bienes que dejaban en herencia un $10 \%$ de los mismos con el objetivo de poder hacer frente a los gastos ocasionados tras su óbito y de cara a conseguir la salvación de su alma. En consecuencia una media de 486 reales eran los que se destinaban a este trascendental cometido. De ellos el gran beneficiado era el clero, ya que se llevaba más de la mitad de estos gastos, el $53,8 \% \%^{22}$, y especialmente el clero parroquial que ingresaba dinero por los derechos de sepultura ${ }^{23}$ y sobre todo por las misas, novenarios, etc., demandadas que representaban el 70,2\% del total de ingresos que recibía el clero, lo cual, por otra parte, resulta lógico si tenemos presente que la misa era el mejor de los sufragios posible ${ }^{24}$ hasta convertirse en "moneda de salvación"25 cuyo último beneficiario era el demandante: su alma.

\footnotetext{
${ }^{19}$ La demanda y presencia de cofradías es menor que en los medios urbanos pero aún así si que se solía solicitar a las cofradías más cercanas, las de los pueblos donde habitaba el difunto/a, como las Cofradías de la Cruz, Ánimas, las cuales cobraban por su salida y misas entre 17 y 13 reales, dependiendo de si los fallecidos eran o no hermanos. En Valladolid por sus asistencias a la comitiva fúnebre se pagaban 33 reales. M. GARCÍA FERNÁNDEZ, Herencia y patrimonio familiar..., op. cit., p. 127.

${ }^{20}$ Aunque como ya se conoce había una gran variedad de precios según el lugar más privilegiado o no de la iglesia de cara a la función última de la salvación eterna, la media desembolsada por las sepulturas se sitúan en 15,7 reales. Como es lógico en Valladolid ciudad la media era más del doble, 34 reales para el siglo XVIII, pero encubriendo grandes diferencias entre las diversas parroquias. Ibídem, p. 102.

${ }^{21}$ Muy inferior a los 28 reales como mínimo que recibían en Valladolid. Ibídem, p. 128.

${ }^{22}$ En los pueblos de Valladolid los porcentajes eran más altos con un 71,5\%. Ibídem, p. 126.

${ }^{23}$ Éstos se repartían entre la fábrica y sus ministros, los curas y beneficiados de esas parroquias. Ibídem, p.102

${ }^{24}$ F. MARTÍNEZ, Muerte y sociedad en la España de los Austrias, Madrid, 1.991, pp.956-979.

${ }^{25}$ M. GARCÍA FERNÁNDEZ, Herencia y patrimonio familiar..., op. cit, p. 69.
} 


\section{CUADRO 3 \\ LAS CANTIDADES DE DINERO QUE RECIBE EL CLERO (reales)}

\begin{tabular}{cccc}
\hline Misas, novenarios, mandas & Sacerdotes, religiosos & Derechos de sepultura & Total reales \\
15.212 & 4.952 & 1.288 & 21.452 \\
$70,9 \%$ & $23,1 \%$ & $6 \%$ & \\
\hline
\end{tabular}

Fuente: A.H.P.L. (82 casos)

\section{EL GASTO POR LA SALVACIÓN SEGÚN LAS RIQUEZAS FAMILIARES.}

La abundante historiografía nos ha demostrado que a mayor riqueza mayor parafernalia y gastos a la hora de enfrentarse a la muerte. En este sentido el estudio que pretendemos realizar en este apartado no constituye a priori ninguna novedad. Sin embargo, al tratarse de una muestra formada sólo por familias campesinas y al poder conocer para cada fallecido/a de toda la trayectoria en la formación del patrimonio y especialmente los bienes líquidos, si consideramos que podemos aportar aspectos relevantes centrados por una parte, en lo que suponían los gastos en entierro, funerales, misas, etc., en relación con los bienes líquidos de los fallecidos y por otra parte, las diferencias entre el propio campesinado a la hora de distribuir estos gastos destinados a la salvación ${ }^{26}$.

Así, a nivel metodológico hemos distribuido los finados en cinco grupos atendiendo a los gastos que realizaron en su entierro, funeral, misas, etc., y los hemos puesto a su vez en relación más que con los bienes patrimoniales con los bienes líquidos ${ }^{27}$.

Un primer grupo de estudio es el constituido por los que gastan menos en entierro, funeral, misas, etc., es decir los situados entre los 0 y los 99 reales. Éstos representan sólo el $8,9 \%$ del total de la muestra y se corresponden con familias campesinas que han fracasado a nivel económico ya que las deudas

\footnotetext{
${ }^{26}$ Ya que como muy bien señala P. Saavedra las comunidades campesinas presentaban una interesante hetereogeneidad, llegando a alcanzar esta poralización social del campesinado en la meseta norte (Tierra de Campos) cotas muy elevadas con un 50\% de los vecinos desposeídos de tierras y ganados.P. SAAVEDA, " El campesinado en la España del A. Régimen: algunas consideraciones", en Historia Social y Ciencias Sociales. S. Castillo, R. Fernández (coordinadores), Lleida, 2.001, págs. 225-245.

${ }^{27}$ Como ya hemos señalado los bienes patrimoniales son menos precisos ya que no se han descontado las posibles deudas e incluyen también los bienes dotales y parafernales del viudo/a. De ahí, que consideramos que es mejor hacer el cálculo con los bienes líquidos del difunto/a.
} 
contraídas superan a los bienes gananciales matrimoniales y a los bienes aportados por los esposos al matrimonio (dotales y parafernales). De ese modo, al no poder disponer de liquidez económica, los gastos destinados a buscar la salvación eterna son mínimos (media de 50 reales) y se reducen únicamente a los más básicos de proporcionar sepultura al difunto/a (gastos ocasionados por el rompimiento de la sepultura, pago de los derechos al sacerdote, cera gastada ${ }^{28}$.

\section{CUADRO 4 \\ EL GASTO POR LA SALVACIÓN SEGÚN LAS RIQUEZAS FAMILIARES (REALES)}

\begin{tabular}{|c|c|c|c|c|c|c|}
\hline $\begin{array}{l}\text { Gastos } \\
\text { funeral, etc. } \\
\text { (intervalo en } \\
\text { reales) }\end{array}$ & $\mathrm{N}^{\mathrm{o}}$ casos & $\begin{array}{c}\text { Gastos } \\
\text { funeral } \\
\text { etc. }\end{array}$ & $\begin{array}{l}\text { Bienes } \\
\text { líquidos }\end{array}$ & $\begin{array}{l}\text { Media } \\
\text { gastos } \\
\text { funeral } \\
\text { etc. }\end{array}$ & $\begin{array}{c}\text { Media } \\
\text { bienes } \\
\text { líquidos }\end{array}$ & $\begin{array}{c}\text { \% de los } \\
\text { gastos } \\
\text { funeral etc. } \\
\text { sobre los } \\
\text { bienes liquidos }\end{array}$ \\
\hline $0-99$ & $\begin{array}{c}8 \\
8,9 \%\end{array}$ & 400 & -6.340 & 50 & $-792,5$ & - \\
\hline $100-399$ & $\begin{array}{c}44 \\
48,9 \%\end{array}$ & 11.094 & 91.062 & 252 & 2.070 & 12,1 \\
\hline 400-699 & $\begin{array}{c}26 \\
28,8 \%\end{array}$ & 13.974 & 144.810 & 537 & 5.570 & 9,6 \\
\hline $700-999$ & $\begin{array}{c}4 \\
4,4 \%\end{array}$ & 2.874 & 26.566 & 718 & $6.641,5$ & 10,8 \\
\hline+ de 1.000 & $\begin{array}{c}8 \\
9 \% \\
\end{array}$ & 11.786 & 200.514 & 1.473 & 25.064 & 5,8 \\
\hline
\end{tabular}

Fuente: A.H.P.L. (90 casos)

\footnotetext{
${ }^{28}$ Por ejemplo, Félix de la Fragua, vecino de Grañeras, cuando fallece en 1783 deja un total patrimonial familiar de tan sólo 786 reales, de los cuales 544 corresponden a bienes aportados por su esposa (520 de dote más 24 que le corresponden del lecho cotidiano) y las deudas contraídas (incluidos los 34 reales gastos en el entierro) suponen 425 reales. De ahí que al final el balance patrimonial sea negativo en 183 reales y el difunto no dejó en herencia bienes líquidos disponibles por lo que sólo se gastó en su salvación lo imprescindible del entierro incluyéndolo en el capítulo de las deudas (sepultura tres reales, derechos de sacerdote 11 reales, libra y media de cera 15,5 reales, la ofrenda u oferta de pan y cera 2,5 reales y los 2 reales de las séptimas acostumbradas), en total 34 reales. A.H.P.L., Antonio Mata, Caja 4463.
} 
El segundo grupo, el más numeroso con un $48,9 \%$ de la muestra, es el que dedica entre 100 y 399 reales, una media de 252 reales, a los gastos ante la muerte y por la salvación. Se trata de difuntos que a base de grandes sacrificios y esfuerzos han conseguido un balance patrimonial positivo y con bienes líquidos que pueden dejar en herencia a sus hijos. Así, la media de bienes líquidos por difunto/a es de 2.070 reales $^{29}$. De ellos el 12,1\% lo dirigen a sufragar los gastos originados por la muerte y la búsqueda de la salvación de su alma.

La partida dedicada a pagar el entierro, honras y cabo de año se lleva el grueso del presupuesto, con un 48,5\% y 127 reales de media ${ }^{30}$, seguida, pero a bastante distancia, por las misas solicitadas principalmente por su alma, el $25,2 \%$, (la media de misas es de 31,2 de las cuales la mayoría, con 28,9 , son las más simples, es decir rezadas de a dos reales cada una) y las ofrendas u "ofertas" de pan y cera y los derechos pagados por llevarla con un $24,8 \%$. También se ha de destacar en un nivel testimonial la presencia de mandas pías $^{31}$ y novenarios $^{32}$.

\footnotetext{
${ }^{29}$ Es el caso de José Conde, vecino de San Pedro de Dueñas, el cual contrajo matrimonio con Lucia Tirados aportando el sólo la cantidad de 1.834 reales (en tierras de cereal, viñas y bienes muebles). Estos escasos bienes ingresados a la nueva célula familiar fueron incrementados durante la vida en común de la pareja obteniendo unos gananciales valorados en 1.241 reales, de los cuales 620 reales le corresponden al finado. De este modo, una vez que fallece sus bienes líquidos se valoran en 2.454 reales (1.834 reales de los aportados al matrimonio más 620 de los gananciales) y de ellos 370 reales (un 15\%) lo dedica a sufragar los gastos de la muerte y la salvación eterna. De todas formas a pesar de significar estos gastos un $15 \%$ se ha de precisar que no llegan a cubrir la totalidad de lo asignado en la mejora del quinto a su mujer (491 reales) con la obligación de que pagase el funeral. En el extremo superior de este grupo de familias campesinas nos encontramos con una minoría ( 8 casos) cuyos bienes líquidos duplican la media estimada conseguidos en su gran mayoría durante la vida conyugal (bienes gananciales) que se adjudican a ellos solos excluyendo a las viudas en el momento de su muerte, de ahí su mayor cuantía. Es lo que sucede con Bernardo de la Huerta, vecino de las Grañeras, el cual contrajo matrimonio con María Fernández en 1733, aportando él ningún tipo de bienes y ella la cantidad de 858 reales (entre dotales y parafernales). Durante los 33 años que duró su matrimonio consiguieron juntar un relevante patrimonio de base agraria tasado en 6.848 reales (las tierras de cereal y las viñas se valoraron en 1.271 reales, la vivienda y dependencias complementarias en 1.910 reales, el ganado en 651 reales y los productos de la despensa en 265 reales) del que descontado las deudas comunes se quedó en 5.371 reales de bienes gananciales, los cuales se adjudicaron sin partir al difunto y entraron a formar parte de las hijuelas a heredar por los 4 hijos, exceptuando el quinto (567 reales) que se dejó para el funeral y el remanente del mismo para la mejora de la viuda. Como los gastos del entierro, funeral, misas, etc,. costaron la cantidad global de 336 reales la viuda sólo se quedó con 231 reales de los 2.685,5 que le correspondían de la mitad de los gananciales. Id., Juan Felipe y Godoy, Cajas 4462 y 4459.

${ }^{30}$ Es lo que sucede en el ejemplo anteriormente descrito donde el entierro supone la cantidad total de 129 reales, destacando el hábito con 44 reales y la asistencia de las cofradía de la villa de Sahagún y sus correspondientes oficios con 63 reales. Ibídem.

${ }^{31}$ Se trata de Ignacio Bartolomé, vecino de las Grañeras, que deja de manda cuatro reales a San Juan de Sahagún. Id., Caja 4.460

${ }^{32}$ Como el de Manuel Merino, vecino también de Grañeras, que deja de bienes líquidos 2.702 reales (1.072 aportados al matrimonio y 1.630 de la mitad de los bienes gananciales), sus gastos de entierro, funeral, misas, etc., suponen la cantidad global de 367 reales y deja dispuesto que se realice un novenario de tres reales cada misa, en total 27 reales. Id. Caja 4462.
} 
En el tercer grupo, dentro del umbral establecido entre 400 y 699 reales de gasto del entierro, funeral, etc., nos encontramos también un importante número de casos, el $28,8 \%$, cuyo gasto medio de cara a la muerte se sitúa en 537 reales -superior al doble que los anteriores- y sus bienes líquidos también serán más del doble, superando la media de los 5.500 reales, en concreto 5.570 reales, con lo cual la parte de capital que se detrae para sufragar los gastos de entierro, funeral, etc., es menor que en el grupo precedente, un 9,6\%. A diferencia de las anteriores son familias campesinas donde los bienes recibidos en herencia serán más importantes que los conseguidos como gananciales durante el matrimonio ${ }^{33}$.

En cuanto al estudio de los gastos efectuados por el funeral, etc., se aprecia cómo las diferencias del grupo anterior a favor de las mayores partidas de dinero destinadas a sufragar el entierro, honras y cabo de año se aminoran (un 39,6\%), adquiriendo más relevancia las cantidades dirigidas a la demanda de misas (un $33,5 \%)^{34}$. Por otro lado, también se observa una ligera subida en las ofrendas u "ofertas" (de 24,8 al 26,4\% y donde la media pasa de 65 reales a 142 reales) $)^{35}$.

\footnotetext{
${ }^{33}$ Incluso nos encontramos con 8 casos donde los bienes gananciales conseguidos durante el matrimonio son negativos, mientras que los dotales y parafernales recibidos en herencia constituyen cantidades importantes. Es el caso de Damiana Lobete, casada con José Conde, vecinos de Sahagún, la cual había aportado a la célula familiar un total de 11.683 reales (procedentes de las legítimas heredadas de sus padres y dos hermanos) consistentes en viñedos, tierras de cereal, casa, eras y bienes muebles. En cambio, el marido sólo había aportado la cantidad de 1.231 reales. A pesar de la importante inyección económica de bienes parafernales, sobre todo de la esposa, cuando en 1783 fallece la mujer y se realizan las cuentas resulta que durante el matrimonio han sido mayores las deudas (3.405 reales) que los ingresos y por ello el balance final ganancial es de -1.005 reales. Además, a los bienes que les correspondían a la difunta se le van a descontar no sólo la parte de las deudas de los gananciales sino también dos censos que están contra los bienes de la misma. Aún así le quedan como bienes líquidos la cantidad de 10.075 reales, de los cuales destina el quinto ( 2.015 reales) al funeral ( 515 reales) y el remanente del mismo (1.500) a su marido. Id.,Caja 4463.

${ }^{34}$ La media de misas demandadas asciende de forma vertiginosa si la comparamos con el grupo anterior (de 31,2 a 79,7). Un ejemplo característico lo tenemos en Josefa Rodríguez, vecina de Sahagún, la cual deja unos bienes líquidos de 7.296 reales (constituidos íntegramente por los dotales y parafernales ya que los gananciales también fueron negativos), su entierro, funeral, etc., costó 641 reales. De ellos 287 fueron dedicados a pagar los gastos del entierro, honras y cabo de año (30 reales de la sepultura, 44 del hábito, 140 de los derechos de los sacerdotes y 73 de cera gastada en el entierro, honras y cabo de año) y 240 reales se dedicaron para costear 80 misas rezadas a tres reales cada una. Ibídem.

${ }^{35}$ Entre los gastos efectuados tras la muerte de Manuel Saldaña, vecino de Sahagún, figura una "oferta" consistente en : "...cinto y diez reales del pan y cera para la oferta de medio año y los días festivos hasta el cumplimiento del año. Cuarenta y cuatro reales del trabajo de llevarla..". Ibídem.
} 
El cuarto grupo es más minoritario, sólo representa el 4,4\% de la muestra, y está configurado por los campesinos/as que a la hora de enfrentarse a la muerte lo hacen con unos gastos entre 700 y 999 reales. De esta forma la media de bienes destinados a la muerte y salvación de su alma se eleva a la cifra nada despreciable de 718 reales (181 reales más que el grupo anterior, lo que equivale a un incremento del 33,7\%). En cambio, sus bienes líquidos no experimentarán el mismo crecimiento, ya que con $6.641,5$ reales de media sólo subirán un 19 , $2 \%$. De ahí, que sea mayor la detracción, un $10,8 \%$, de los gastos del entierro, funeral, misas, etc., respecto a los bienes líquidos, los cuales son fruto también más que del esfuerzo en la vida conyugal de la herencia recibida ${ }^{36}$.

En el estudio más pormenorizado de la estructura de los gastos del entierro, funeral, etc., la característica más sobresaliente es la mayor cantidad de dinero dedicadas a las misas (la media de las mismas se incrementa a 118,5 reales) sobrepasando por primera vez a las destinadas al pago del entierro, honras y cabo de año. Así, las misas significan el 41,7\% de los gastos con 299,5 reales de media y los gastos de entierro, honras y cabo de año descienden al $26,3 \%{ }^{37}$. Por su parte la ofrenda u "oferta" también se mejora aunque de forma más tímida (un $27,1 \%$ y 195 reales de media) y finalmente, hay que destacar las mandas religiosas (con un $4,6 \%)^{38}$.

El último grupo objeto de estudio, el que efectúa los mayores gastos en su muerte y salvación eterna, por encima de los 900 reales, también representa una minoría de las familias campesinas, el $9 \%$ de la muestra. Ahora bien, las medias dedicadas al entierro, funeral, misas, etc., duplican las del anterior grupo y se

\footnotetext{
${ }^{36}$ Es lo que ocurre, por ejemplo, con José Rojo, vecino de San Pedro de las Dueñas, el cual aportó al matrimonio con Micaela Felipe la cantidad de 6.913 reales y ella de 7.116 reales. Sin embargo, en 1781 cuando fallece el esposo y se hace recuento de los bienes obtenidos durante el matrimonio, gananciales, sólo se valoran en la cantidad de 861 reales. Más extremo es el caso de Jerónimo Felipe, vecino también de San Pedro de Dueñas, el cual al quedarse viudo con tres hijos decidió casarse en segundas nupcias en 1773 con Córdula Espeso ( prometiéndola a la futura esposa las "vistas "que se acostumbran a dar en estos casos ). El aportó al nuevo matrimonio la relevante cantidad de 10.015 reales (donde destacan las 6 viñas tasadas en 1.705 reales, el ganado en 1.647 y particularmente " 19 cuadros grandes y pequeños de diferentes pinturas en dos mil tres reales y doce maravadies"). Y ella tan sólo 2.535 reales (de los cuales sólo 200 fueron dotales). En los doce años que duró su matrimonio las deudas fueron mayores que los escasos ingresos y así el balance final patrimonial es negativo en 4.075 reales, los cuales se descuentan de los bienes llevados al matrimonio por el marido fallecido quedándole sólo la cantidad de 5.940 reales y a éstos se vuelven a restar los 375 reales de la manda de las vistas que la prometió cuando se casaron y tienen cabimiento en la décima parte de los bienes. Id., Cajas 4461 y 4464.

${ }^{37}$ Además del mayor número de misas solicitadas hay que tener presente que su coste también es mayor, ya que por ejemplo las mismas que se van a realizar al citado Jerónimo Felipe se calculan al pago de tres reales cada una. Ibídem.

${ }^{38}$ Como la efectuada por José Rojo consistente en "... una carga de trigo a los frailes de Grajal...". Ibídem.
} 
sitúan en la relevante cantidad de 1.473 reales ( muy próximos a los 2.070 reales de media de bienes líquidos que les quedaba para dejar en legítimas a sus herederos el grupo ya estudiado y que representaba casi a la mitad del campesinado de la muestra ${ }^{39}$. Además, al ser los bienes líquidos mucho más cuantiosos (media de 25.064 reales) la detracción de los gastos de entierro, funeral, etc., sobre los mismos es la más reducida de todo los casos estudiados, tan sólo un 5,8\% ${ }^{40}$.

En la estructura interna de estos gastos funerarios, se reafirma la tendencia ya observada en el grupo precedente en cuanto que son las cantidades destinadas a las misas las que suponen el $54,9 \%$ del total de gastos, disminuyendo el valor porcentual del dinero de los entierros, honras y cabo de año a tan sólo el 18,2\%. Así las misas demandadas casi se triplican respecto al grupo anterior (323 de media) y lo mismo sucede con las cantidades medias (de 299, 5 reales a 808,5 reales $)^{41}$. En cambio, los gastos de entierro, honras y cabo de año no van a superar la media de los 269 reales $^{42}$. Por su parte, las ofrendas u "ofertas" también se duplicarán (de 195 reales de media del grupo anterior a 394 reales) ocupando el segundo lugar de la estructura de gastos, con un $26,7 \%$ y desplazando al tercer puesto al entierro, honras y cabo de año ${ }^{43}$.

${ }^{39}$ Los gastos más elevados de entierro, funeral, misas, etc., no son los que tienen mayores bienes líquidos disponibles, sino los de Bernardo Ávila, casado por tercera vez con Marcela García, vecinos de Sahagún, con la cantidad de 1.724 reales, cuando sus bienes líquidos son sólo de 12.456 reales. Id., Caja 4463.

${ }^{40}$ Estos altos bienes líquidos son fruto tanto de los bienes heredados (dotales y parafernales) como de los logrados en la vida conyugal (bienes gananciales). De todas formas, existen ejemplos donde las mayores cantidades corresponden a los heredados o bien a los gananciales. Del primer caso traemos a colación a Domingo Herrero, vecino de Calzada del Coto, el cual cuando se casó en segundas nupcias, en 1754, con Alfonsa López llevó al matrimonio la cantidad de 31.284 reales y ella tan sólo la de 1.132 (se trataba de un matrimonio de conveniencia donde el viudo buscaba una nueva esposa y madre para un hogar que tenía 6 hijos). Quince años mas tarde fallece Domingo y se procede a realizar el balance de cuentas resultando unos bienes gananciales de 13.911 reales, de los que la mitad corresponden al marido fallecido y la otra mitad a la viuda. Y del segundo caso podemos citar a Andrés González Martínez, vecino de Sahagún, el cual había aportado al matrimonio 7.097 reales de bienes recibidos en herencia y su mujer, Catalina de Celada, 12.448 (de los cuales 463 de dote en el momento de contraer matrimonio y el resto parafernales). A estos importantes ingresos se une una buena gestión durante la vida conyugal como lo confirma que la cantidad de bienes gananciales sea valorada en el momento de la muerte del esposo en 46.931 reales. De ahí, que los bienes líquidos del marido se sitúen en 30.562 reales y de ellos la mayor parte, el $76,8 \%$, hayan sido obtenidos como gananciales. Id. Cajas 4460 y 4465.

${ }^{41}$ El mayor número de misas corresponde al ya citado Bernardo Ávila con 450 a tres reales. Ibidem.

${ }^{42}$ El mayor gasto es el de Manuel Prieto Malaguero, vecino de Sahagún, con 336 reales ( 30 de los derechos de sepultura, 4 del hábito y 263 de los derechos pagados por las honras y cabo de año). Id., Caja 4459.

${ }^{43}$ Los mayores gastos en ofertas son de nuevo los de Miguel Prieto Malaguero, en total 704 reales (368 de la cera y 336 del pan). Ibídem. 
Del anterior estudio podemos establecer las siguientes conclusiones: por una parte, no es nada novedoso el afirmar que a mayor nivel de bienes

\section{CUADRO 5 \\ DISTRIBUCIÓN DE LOS GASTOS POR LA SALVACIÓN SEGÚN LAS RIQUEZAS FAMILIARES (Medias reales y \%)}

\begin{tabular}{cccccccc}
$\begin{array}{c}\text { Intervalo en } \\
\text { reales }\end{array}$ & $\begin{array}{c}\mathrm{N}^{\text {o }} \\
\text { casos }\end{array}$ & $\begin{array}{c}\text { Entierro, honras } \\
\text { y cabo de año }\end{array}$ & Misas & Ofertas & $\begin{array}{c}\text { Séptimas } \\
\text { acostumbradas }\end{array}$ & Mandas & Novenarios \\
\hline \multirow{2}{*}{$0-99$} & 4 & 36,7 & 0 & 0 & 2 & 0 & 0 \\
& & $91,8 \%$ & $0 \%$ & $0 \%$ & $8,2 \%$ & $0 \%$ & $0 \%$ \\
$100-399$ & 40 & 127,3 & 66 & 65 & 2,3 & 0,2 & 1,3 \\
& & $48,5 \%$ & $25,2 \%$ & $24,8 \%$ & $0,8 \%$ & $0,2 \%$ & $0,5 \%$ \\
$400-699$ & 26 & 213 & 180,3 & 142 & 2,3 & 0 & 0 \\
& & $39,6 \%$ & $33,5 \%$ & $26,4 \%$ & $0,5 \%$ & $0 \%$ & $0 \%$ \\
$700-999$ & 4 & 189 & 299,5 & 195 & 2 & 33 & 0 \\
& & $26,3 \%$ & $41,7 \%$ & $27,1 \%$ & $0,3 \%$ & $4,6 \%$ & $0 \%$ \\
+ de 1.000 & 8 & 268,5 & 808,5 & 394 & 2,5 & 0 & 0 \\
& & $18,2 \%$ & $54,9 \%$ & $26,7 \%$ & $0,2 \%$ & $0 \%$ & $0 \%$ \\
\hline
\end{tabular}

Fuente: A.H.P.L. (82 casos)

\section{CUADRO 6 \\ MISAS DEMANDADAS SEGÚN LA RIQUEZA FAMILIAR}

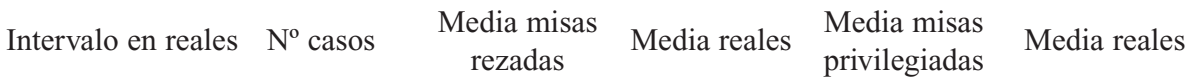

\begin{tabular}{cccccc}
\hline $0-99$ & 4 & 0 & 0 & 0 & 0 \\
$100-399$ & 40 & 28,9 & 59,5 & 2,3 & 6,5 \\
$400-699$ & 26 & 78,5 & 173 & 1,2 & 7 \\
$700-999$ & 4 & 118 & 298 & 0,5 & 1,5 \\
+ de 1.000 & 8 & 323 & 808,5 & 0 & 0 \\
\hline
\end{tabular}

Fuente: A.H.P.L. (82 casos) 
patrimoniales mayor gasto dedicado a la muerte y a la búsqueda de la salvación eterna ${ }^{44}$. Sin embargo, si consideramos una aportación el poder constatar que más que los bienes patrimoniales globales son los bienes líquidos resultantes de los difuntos los que incidían en el gasto dedicado al entierro, funeral, misas, ofrendas, etc. Y desde este tipo de análisis se vuelve a ratificar de forma más precisa la conclusión ya expuesta de a mayores bienes líquidos de los difuntos/as campesinos mayores cantidades destinadas a hacer frente a los gastos de la muerte y la salvación eterna. Produciéndose entre el propio campesinado una gran heterogeneidad que iba desde los sólo 50 reales o 252 reales de media que podía dedicar más de la mitad del campesinado a los 1.473 reales de media que se podía costear una minoría más pudiente. Además, se daba la particularidad que cuanto mayores fuesen las cantidades orientadas a esta trascendental función suponían una menor detracción de los bienes líquidos que se iban a destinar a legítimas a los herederos. Y por otra parte, tal como se ha analizado en el estudio anterior, no eran los gastos destinados al entierro, honras y cabo de año, los que iban a marcar las diferencias de riquezas entre el propio campesinado, ya que éstos tenía un límite bastante bien establecido, sino que van a ser las ofrendas u "ofertas" y sobre todo las demanda de misas centradas en la salvación de su alma las que van a establecer dichas pautas diferenciales. De ahí, que va a ser entre las 31 misas de media que se van a realizar a casi la mitad del campesinado y las 323 de media de los campesinos más pudientes donde éstos intentarán utilizar "la moneda espiritual" de las misas de cara a una mejor "compra de la salvación"45.

\section{EL SIGNIFICADO DE LOS BIENES DIRIGIDOS A LA MUERTE Y SALVACIÓN EN RELACIÓN CON LAS LEGÍTIMAS.}

Como es lógico la detracción de bienes destinados a la muerte y salvación del alma resulta ser mayor si la ponemos en comparación con las legítimas dejadas a los hijos, ya que una parte de la riqueza se dirige a familiares y sobre todo a la viuda/o dentro de la mejora del tercio y particularmente del quinto de

\footnotetext{
${ }^{44}$ Ver estudios ya citados y sobre todo el de M. GARCÍA FERNÁNDEZ, Herencia y patrimonio.., op. cit..

${ }^{45}$ Según M. García Fernández, "...la misa, como "moneda espiritual", tendía a tener propicio al mundo de ultratumba, y vinculaba estrechamente la salvación de todos a la relación de ayuda y no olvido bidireccional (presencia viva de mortales y quienes habían traspasado ya el umbral) en la sensibilidad colectiva de ambas comunidades...". Ibídem p. 66.
} 
libre disposición. Ahora bien, la mejor forma de analizarlo es a través de los diversos grupos ya señalados.

En los que los gastos de la muerte, funerales, etc. se sitúan entre 0 y 99 reales la detracción sobre la herencia dejada a los hijos en los casos donde los bienes líquidos no resultan ser negativos llega a suponer un $25 \%{ }^{46}$.

En el segundo grupo, los comprendidos entre 100 y 399 reales de gasto, la detracción sobre los bienes dejados en herencia a los hijos significa un 14,5\% ( 2,4 puntos a mayores respecto a los bienes líquidos). Los hijos, cuya media es de 2,3 por familia, recibe una media de bienes en herencia de 735 reales (la media del entierro, funeral, etc. era de 252 reales) ${ }^{47}$.

En los del tercer grupo, de 400 a 699 reales, la detracción de bienes se sitúa en $11,7 \%$ (un 2,1\% más que sobre los bienes líquidos). Por su parte los hijos, cuya media por familia es más alta, con 3,4 hijos, que en los anteriores casos, obtienen también mayores legítimas (1.361 reales de media cuando la media del entierro, funerales era de 537 reales ${ }^{48}$.

\footnotetext{
${ }^{46}$ Es lo que sucede con Pedro Conde, vecino de Bercianos del Real Camino, el cual sólo dispone de 230 reales de bienes líquidos (64 reales aportados al matrimonio y 166 de gananciales), de ellos 46 se dedican a pagar los gastos del entierro, funeral, etc. (el quinto) y sólo quedan 184 reales para repartir en legítimas a sus cuatro hijos. A.H.P.L., Caja 4460.

${ }^{47}$ Como ejemplo tenemos el de Santiago Quintana, casado con Francisca Pérez, vecinos de Bercianos del Real Camino, al cual se adjudican todos los bienes gananciales (4.093 reales) y de ellos se restan 500 reales de la manda de la mitad de la casa a su mujer y 257 reales de gastos del entierro, funeral, etc., con lo que quedan 3.336 reales que se reparten entre 5 hijos a 667 reales cada uno. El caso más extremo es el de Andrés de la Encina, vecino de Calzada del Coto, el cual reparte entre sus tres hijos 1.305 reales a cada uno. Pero con la particularidad de que a los dos hijos mayores (varones) les ha adelantado ya en bienes sobre todo mobiliarios cuando contrajeron matrimonio 572 reales a Andrés y 681 a Santos. Id., Caja 4462 y 4465.

${ }^{48}$ Así, por ejemplo, lo normal es el caso de Damiana Lobete, vecina de Sahagún, a la cual la quedan para repartir entre sus cinco herederos, tras descontar los 2.015 reales que suponen el quinto destinado al entierro, funeral, etc., (515 reales) y el remanente dejado a su marido (1.500 reales) y los 1.000 reales de la manda de una casa que hizo a un hijo, la cantidad de 7060 reales con los que toca cada uno a 1.412 reales. No obstante, también en este grupo se producen casos extremos donde se deja a cada hijo casi el doble de la media establecida. Así, Marcela Calvo, vecina de Bercianos del Real Camino, en el momento de su fallecimiento tiene unos bienes líquidos valorados en 12.081 reales. De ellos se destina el quinto al funeral, entierro, (en total unos gastos que con 589 reales estarían dentro de la media del grupo) y el remanente del mismo (1.827 reales) a la mejora de su marido. Además, se bajan también 379 reales de mejoras hechas a sus nietos (sobre todo de ganado) y que han tenido cabida en el tercio. En definitiva aún quedan para repartir entre los 4 hijos 9.286 reales, tocando cada uno a 2.321 reales. Id., Cajas 4461 y 4459 .
} 
En los que se sitúan en el cuarto grupo, gastos de entierro, funeral, etc., entre 700 y 999 reales, estos dispendios llegan a suponer porcentajes más elevados respecto a las legítimas de los hijos que en el grupo anterior (de nuevo como en los del segundo grupo de campesinos el 14,5\%, es decir un 3,7\% a mayores en relación con la parte de detracción de los bienes líquidos ${ }^{49}$ ).

Y finalmente, en el grupo de mayores gastos a la hora de afrontar su muerte y salvación, por encima de los 1.000 reales, éstos significan también menos a la hora de ponerlos en relación con los bienes dejados en legítimas a los hijos. Así sólo serán un 6,7\% (incrementándose en tan sólo $0,9 \%$ respecto a lo que suponían en los bienes líquidos, en consecuencia son más escasos los bienes destinados a mejoras ) y los hijos (la media de los mismos también será la más alta de la muestra con 3,75 ) heredarán con 5.828 reales una media muy superior (casi cuatro veces más) a los gastos de entierro, funeral, etc, ( 1.473 reales $)^{50}$.

\section{CUADRO 7 \\ RELACIÓN DE LOS BIENES DESTINADOS A LA SALVACIÓN CON LAS LEGÍTIMAS HEREDITARIAS (reales)}

\begin{tabular}{|c|c|c|c|c|c|c|}
\hline $\begin{array}{l}\text { Intervalo } \\
\text { reales }\end{array}$ & Casos & $\begin{array}{c}\text { Gastos } \\
\text { funeral, etc. }\end{array}$ & $\begin{array}{l}\text { Legítimas dejadas } \\
\text { a los hijos }\end{array}$ & $\begin{array}{c}\% \text { gastos funeral etc. } \\
\text { sobre legítimas } \\
\text { hijos }\end{array}$ & $\begin{array}{c}\text { Media gastos } \\
\text { funeral etc. }\end{array}$ & $\begin{array}{c}\text { Media } \\
\text { herencia } \\
\text { dejada a } \\
\text { cada hijo/a }\end{array}$ \\
\hline $0-99$ & 2 & 92 & 368 & $25 \%$ & 46 & 46 \\
\hline $100-399$ & 42 & 10.431 & 72.040 & $14,5 \%$ & 248,3 & 735 \\
\hline $400-699$ & 26 & 13.974 & 119.762 & $11,7 \%$ & 537 & 1.361 \\
\hline $700-999$ & 2 & 1.412 & 9.718 & $14,5 \%$ & 706 & 1.619 \\
\hline+ de 1.000 & 8 & 11.786 & 174.830 & $6,7 \%$ & 1.473 & 5.828 \\
\hline
\end{tabular}

Fuente: A.H.P.L. (82 casos)

\footnotetext{
${ }^{49}$ Ello guarda relación con la importancia que tenían en este grupo los matrimonios en segundas nupcias y las "vistas" que estaba obligado a dar el esposo cuado se casaba con su nueva mujer por ser viuda, ya que estos bienes se restaban de los líquidos a partir entre los hijos.

${ }^{50}$ Es lo que sucede con Domingo Herrero Rojo, vecino de Calzada del Coto, el cual tiene unos biees líquidos valorados en 38.239 reales y de ellos se restan 2.513 (1.559 de gastos de entierro, funeral, etc. y 954 de mandas) quedando para dividir entre los 6 herederos 35.726, con lo que toca a cada uno 5.954 reales. A.H.P.L., Caja 4460.
} 
En definitiva, del anterior análisis se deduce en primer lugar, que en general en todos los grupos del campesinado la detracción de bienes dedicados a la muerte y la salvación es mayor ( suponiendo entre un $6,7 \%$ y un $14,5 \%$ y en consecuencia entre un $2 \%$ y $3 \%$ más) si la ponemos en relación con los bienes no líquidos del difunto/a sino con los más relevantes de cara a la formación de los nuevos núcleos familiares y su reproducción social y económica, es decir con los dejados en legítimas a sus hijos. En segundo lugar, en la mayoría del campesinado, el $77,1 \%$ de la muestra, se puede estimar que en torno al $2 \%$ de los bienes líquidos de los difuntos se escapan de las legítimas en mandas y sobre todo mejoras del remanente del quinto una vez satisfechos los gastos del entierro, funeral, etc, que van a parar a sus respectivos esposos. Cantidades no muy significativas pero que tienen su relevancia al tratarse de herencias modestas recibidas por los hijos. Y en tercer lugar, será de nuevo en las familias campesinas de mayor nivel económico donde los elevados gastos dedicados a la muerte y salvación de su alma signifiquen menos de cara a la detracción de los altos bienes que dejan en herencia a sus descendientes. Además, tampoco dirigirán grandes cantidades en mandas y mejoras a sus esposos, lo cual en parte resulta lógico ya que éstos tenían mayores medios económicos, aparte de los de sus hijos que también les podían socorrer en caso de urgente necesidad, para poder hacer frente a la futura soledad y estado de viudez.

Ahora bien, llegados a este punto donde ya se ha remarcado que en torno a un $10 \%$ de los bienes líquidos, dos puntos más si lo ponemos en relación con las legítimas de los hijos, de los campesinos se dirigían a sufragar los gastos de la muerte y salvación, cobra especial trascendencia el tratar de averiguar con qué tipo de bienes se hacía frente a los denominados gastos de la muerte, ya que dependiendo de unos u otros esta relevancia será aún mayor de cara a las futuras familias y su reproducción económica y social. Aunque se trata de un tema difícil de averiguar ya que a la hora de rendir cuentas estos gastos de entierro, funeral, etc., se engloban con el pago de las deudas comunes sin especificar de forma concreta y lo mismo sucede cuando en el inventario de los bienes postmortem se anota en la parte izquierda los adjudicatarios de los bienes, sin embargo, teniendo en cuenta lo señalado y que el pago en bienes, que debían previamente ser vendidos, dependía lógicamente del volumen de los gastos de entierro, funeral y de las deudas contraídas podemos adentrarnos en el estudio planteado. Así, los tipos de bienes con los que se hace frente a estos gastos son principalmente productos agrarios, ganadería y bienes raíces (fundamentalmente 
tierras) y en menor medida el resto de los bienes mobiliarios. Ahora bien, el mayor peso de unos $\mathrm{u}$ otros bienes ( productos agrarios, raíces y ganado) guardaba una estrecha relación con el tipo de deuda que había que saldar. De este modo, cuando sólo se tenía que hacer frente a los gastos ocasionados por la muerte (funeral, entierro, etc.) y salvación del alma éstos se pagaban con el dinero obtenido de la venta de los productos agrarios (vino y cereal recogido) y de las reses ganaderas que hiciesen falta ${ }^{51}$. En cambio, cuando se engloban los pagos del funeral con otros tipos de mandas, deudas o con el quinto de libre disposición, entran en juego además de los bienes especificados los bienes raíces, dependiendo la cuantía de éstos de la mayor o menor cantidad a $\operatorname{pagar}^{52}$.

Por lo tanto, sí podemos concluir afirmando, aunque de forma muy provisional por lo limitado de la muestra, que el tipo de bienes que van a parar sobre todo al clero y se escapan de la herencia dejada a sus hijos/a son fundamentalmente productos agrarios obtenidos en las cosechas (vino, cereal) y reses ganaderas (particularmente de ganado menor). Bienes éstos que son

${ }^{51}$ Sólo disponemos de dos casos donde se relacionan únicamente los gastos del funeral, entierro, etc., sin mezclar con el pago de otras deudas. En el primero se pagan los gastos del funeral de Bernardo de Ávila, valorados en 1.724,5 reales, vecino de la villa de Sahagún en 1783, de la siguiente forma: 392 reales de la venta de vino y el resto con dinero procedente la venta de ganado (sobre todo lanar que compone el grueso de la cantidad, exceptuando una pollina de color negro de 260 reales). Y en el segundo caso, el de José de la Mencía, vecino también de la villa de Sahagún, se pagan los gastos del funeral, 144 reales, con la venta de 42 cántaras de vino mosto. Id., Caja 4463.

${ }^{52}$ Así los gastos del funeral, entierro, etc. (1.559 reales) y las mandas a su mujer, hijas y nietos, (tasadas en 793 reales) de Domingo Herrero Rojo, vecino de Calzada del Coto, se pagan con vino (280 reales), centeno (300 reales), ganado lanar ( 48 corderos y corderas que el difunto mando a sus 24 nietos, valorados en 720 reales ) y el resto con tierras. Los gastos de funeral y de deudas comunes de forma indistinta se sufragan con los bienes señalados aunque a veces se hace sólo con bienes raíces, como por ejemplo, cuando se paga el funeral (287 reales) y deudas (1.909) de Juana Santos, vecina de Sahagún, se hace con dos viñas. Y finalmente, cuando se incluye de forma indiferenciada con los gastos ocasionados por la mejora efectuada del remante del quinto a su esposo/a una vez descontados el costo del funeral, tienen mayor presencia los bienes raíces, casas y sobre todo tierras. Es lo que sucede, por ejemplo, con los gastos de José Conde, vecino de San Pedro de las Dueñas, que mejora a su mujer con el remanente del quinto una vez descontados los gastos del funeral. Éste supone 370 reales y los 121 restantes constituyen la mejora a la viuda, la cual recibe la cantidad total de 1.159 reales (lecho cotidiano, gananciales y mejora del quinto) todos ellos en bienes raíces (una casa y una viña) a excepción lógica del lecho cotidiano valorado en 48 reales y consistente en "...una cama rasa con su encordeladura y delantera, jergón de estopa, dos sábanas de los mismo. Un cobertor azul con su fleco y dos almohadas de lienzo...". Id., Cajas 4462 y 4463. 
mucho más fáciles de vender de forma rápida, adquieren una alta cotización en la segunda mitad del siglo XVIII ${ }^{53}$ y afectan de forma más tenue a la estructura básica de los patrimonios familiares, formada por los bienes raíces, siendo más fácil poder reemplazarlos bien mediante la compra o bien mediante el sistema de aparcería o renta ${ }^{54}$. De todas formas, estos bienes destinados a sufragar los gastos de la salvación no dejan de tener su relevancia y especialmente en las economías familiares campesinas más modestas.

\footnotetext{
${ }^{53}$ Según nos demuestra José M. Pérez García para la Vega Baja del Esla con un incremento de los precios de las reses ganaderas (sobre todo de las ovejas) y del trigo pasando de un índice 100 en 1720/29 a 207,7 en 1760/68. Ver JOSÉ M. PÉREZ GARCÍA, "Evolución de los niveles de vida en la vega del Esla entre 1700 y 1850", en Un modelo social leonés en crecimiento: La Vega Baja del Esla entre 1700 y 1850, León, 1.998, pág. 163.

${ }^{54}$ El pago de las deudas con ganado por parte del campesinado era una constante muy generalizada en la provincia de León durante el A. Régimen ya que era una forma de saldar las deudas contraídas con el burgués comerciante cediéndole a éste el ganado, incluso mayor, de su propiedad , el cual se podía volver a recuperar mediante el sistema de aparcería o el pago de una renta y de esta forma se conseguía mantener intacto el patrimonio raíz. Ver L. RUBIO PÉREZ,"la burguesía...", p. 243-44. J. M. BARTOLOMÉ BARTOLOMÉ, Vino y viticultores en El Bierzo. Sociedad y estructuras económicas durante el siglo XVIII, León, 1.996, págs. 232 y ss.
} 